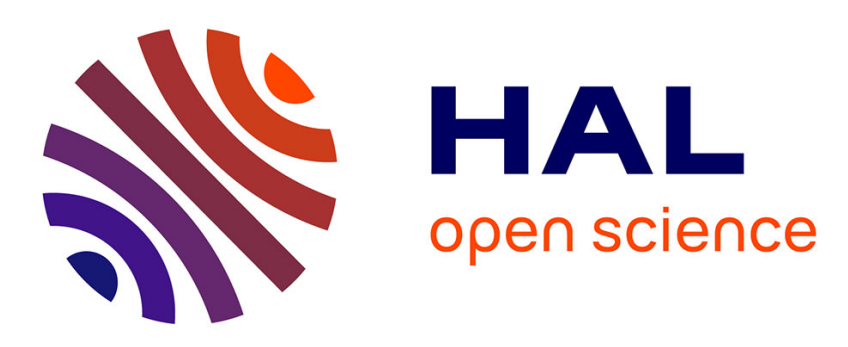

\title{
Near-optimal use of a MRE export cable considering thermal and techno-economic aspects
}

Charles-Henri Bonnard, Anne Blavette, Salvy Bourguet, Thomas Soulard, Yves Perignon

\section{- To cite this version:}

Charles-Henri Bonnard, Anne Blavette, Salvy Bourguet, Thomas Soulard, Yves Perignon. Nearoptimal use of a MRE export cable considering thermal and techno-economic aspects. IEEE ISGT Europe 2020, Oct 2020, Delft, Netherlands. pp.955-959, 10.1109/ISGT-Europe47291.2020.9248908 . hal-02992269

\section{HAL Id: hal-02992269 \\ https://hal.science/hal-02992269}

Submitted on 6 Nov 2020

HAL is a multi-disciplinary open access archive for the deposit and dissemination of scientific research documents, whether they are published or not. The documents may come from teaching and research institutions in France or abroad, or from public or private research centers.
L'archive ouverte pluridisciplinaire HAL, est destinée au dépôt et à la diffusion de documents scientifiques de niveau recherche, publiés ou non, émanant des établissements d'enseignement et de recherche français ou étrangers, des laboratoires publics ou privés. 


\title{
Near-optimal use of a MRE export cable considering thermal and techno-economic aspects
}

\author{
C.-H. Bonnard ${ }^{+}$, A. Blavette ${ }^{+, *}$ \\ SATIE lab. ${ }^{+} /$CNRS $^{*}$, Université de Rennes, Rennes, France. \\ Charles-Henri.Bonnard@ENS-Rennes.fr \\ Anne.Blavette@ENS-Rennes.fr
}

\author{
Salvy Bourguet \\ IREENA lab., Université de Nantes, Saint-Nazaire, France \\ Salvy.Bourguet@Univ-Nantes.fr
}

\author{
Thomas Soulard $^{\&}$, Yves Perignon ${ }^{\&}, \%$ \\ LHEEA lab. ${ }^{\&}, / C N R S^{\%}$, École Centrale de Nantes, Nantes, France \\ Thomas.Soulard@EC-Nantes.fr, Yves.Perignon@EC-Nantes.fr
}

\begin{abstract}
Due to the ever-increasing electricity demand, along with the need to reduce the dependence on fossil or nuclear resources, a growing amount of renewable energy is integrated in the energy mix of many countries. However, the cost-effective integration of wave energy remains difficult as its cost is still not competitive compared with other energy sources. This paper deals with the energy production management of a simulated wave energy converter farm based on point absorbers that could be installed in the vicinity of the SEM-REV site. The approach considers the electrothermal behaviour of the export cable in combination with techno-economic aspects. The method can be used to extend the power export capability of a test site at no cost, which could be very interesting to install more marine renewable energy (MRE) converters and/or of greater rated power. Our study shows that exploiting the thermal inertia of a wave farm submarine export cable, while also considering techno-economic aspects, may lead to an increase of $18 \%$ in the annual energy production without modifying this cable.
\end{abstract}

Index Terms-Energy production management, Marine renewable energy, Submarine cable, Wave energy farm.

\section{INTRODUCTION}

Due to the ever increasing electricity demand, along with the need to reduce the dependence on fossil or nuclear resources, a growing amount of renewable energy is integrated in the energy mix of many countries [1]. Among these, numerous maritime countries consider developing marine renewable energy (MRE) farms, and have already deployed small-scale test sites, e.g. SEM-REV, BIMEP, etc. [2]. It is likely that these test sites managers would be interested in maximising the use of their existing infrastructure by increasing the allowed installed power capacity, while also considering the economic yield of this extension. It is important to emphasize that the currently used design methods are based on electrical current constraints as already mentioned in previous papers [3], [4], rather than on thermal constraints. In addition, they are generally based on (near-)worst case, steady-state conditions, which is quite

This work was conducted in the frame of the BlueGrid project, funded by the Brittany Regional Council and the ENS-Rennes, and in the frame of the ORIGAMI project, funded by WEAMEC. It is worth mentioning that this work could not have been possible without the help of Ecole Centrale de Nantes, LHEEA lab, which provided us with data on sea-state sequences of the SEM-REV test site and precious information on the export cable. conservative for elements benefiting from large thermal inertia such as subsea cables, thanks to their surrounding soil. In other words, a cable may, without exceeding its maximum allowed temperature, transmit temporarily more current than its rated value [5]. One can see two main impacts of taking advantages of this opportunity : 1)extend farms or test sites without modifying the existing infrastructures, and 2) modify the design rules of electrical infrastructures for future farms (floating wind turbine, Wave energy converter WEC, etc.). This paper focuses in particular on the first point. Indeed, the proposed study deals with a wave farm export cable, and is intended to quantify the additional amount of energy that could be transmitted through such an existing cable 1) without exceeding the maximum admissible temperature and 2) considering techno-economic aspects.

\section{Modelling}

\section{A. Energy production of a wave farm}

Case studies developed in this paper consider a modelled point absorber-based WEC farm that could be installed in the vicinity of the SEM-REV site, i.e. the French multi-technology open sea testing site [6]. Energy production has been calculated using a wave-to-wire (W2W) model that has been implemented under Matlab-Simulink ${ }^{\circledR}$ [7]. We considered a farm that can be composed of up to 36 identical 1 MVA heaving buoys controlled passively, as described in [8], [9]. The power generated by the WEC farm has been determined considering a full year sea-state sequence of the SEM-REV site, where data was measured by measurement buoys or reconstructed using HOMERE database [10]. Note that the value of the WECs damping factor has been calculated to maximize the energy production of each sea-state included in the 12-month sequence. In other words, the value of the damping factor is constant for each of the 143 different pairs of wave height $H_{s}$ (in $\mathrm{m}$ ) and peak period $T_{p}$ (in s) that are used to build the whole sea-state sequence, i.e. from June 2014 to June 2015, and that are presented in the scatter matrix shown in Fig 1. The wave power is calculated based on these statistical indices $\left(H_{s}\right.$ and $\left.T_{p}\right)$, and represents an approximation of the real wave power encountered at this test site [11]. The active 


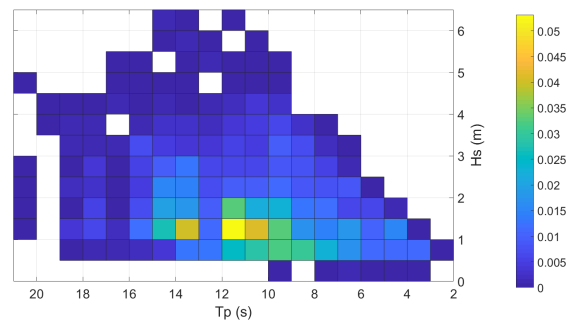

Fig. 1. SEM-REV wave resource scatter matrix showing the sea-state occurrence ratio (between 0 and 1) over the 12-month period considered in this paper. The values of $H_{s}$ and $T_{p}$ have been averaged over 5-hour periods

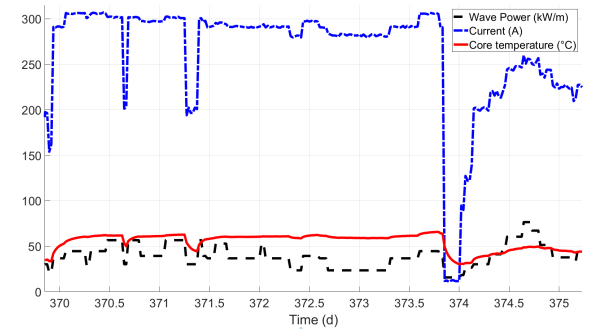

Fig. 2. Zoom of the RMS current profile generated by a WEC farm composed of 11 WECs considering a sequence of sea-states. One can see the high current fluctuations while the cable core temperature shows slower variations

power flowing through the cable, and based on the mean power of the wave front $P_{m}$ (in $\mathrm{W} / \mathrm{m}$ ), is estimated over periods of 30 minutes using $P_{m}$ is estimated over periods of $30 \mathrm{~min}$ using $P_{m}=420 \times H_{s}^{2} \times T_{p}[12]$.

\section{B. Thermal modelling of the export cable}

To reinforce the applicative aspect of our method, which considers real sea-states data of the SEM-REV site, and to focus on a real-life example, our case studies considered the $24 \mathrm{~km}, 20 \mathrm{kV}$ export cable, which is physically installed in the SEM-REV test-site [6]. As in previous studies, the cable core temperature is calculated using an experimentally-validated 2D electro-thermal model developed in Matlab [4], [5]. The whole model, which is composed of the cable and the soil, has been discretized into a thermal equivalent electric circuits composed of thermal resistances and thermal capacitances. This approach, which is used to model thermal transient of varieties of devices, has already proved its worth in terms of the accuracy of the results and reduced computing time [13]-[15]. In addition, it allows to model the heat diffusion within the cable and the soil in order to calculate the timetemperature profile of the cable. It is important to note that the temperature changes are smoothed by the thermal inertia of the cable and the soil. This model helped us to evaluate the cable current carrying capacity $I_{c c} \approx 330$ A that can be transmitted continuously without exceeding the maximum temperature $T_{\max }=90{ }^{\circ} \mathrm{C}$ for these XLPE-insulated cables.

\section{Economic models}

Wave energy converter technologies are not yet mature, and due to the lack of existing wave energy farms and industrial WECs, operational experience feedback and precise technoeconomic figures are unavailable. However, in 2014, Sandia National Laboratories developed its Marine Energy Conversion reference models, where a comprehensive estimation of the CAPEX and OPEX related to point absorber-based WEC farms is presented [16].This served as a baseline for our proposed techno-economic study in which we considered that WEC technologies were available on the market and had reached an industrial production level. Our approach is based on simple techno-economic models which may require to be refined by economists, as well as once more realistic figures become available. It is worth mentioning that we did not take into account the export cable costs, nor the rest of the wave farm infrastructure (e.g. umbilicals, substations, etc.), as they are supposed to be already installed in this virtually available WEC farm, i.e. the farm is not physically implemented and the presented figures are only the results of numerical simulations. The starting point is the evaluation of the annual energy production $(A E P)$ of additional number of WECs $N_{W E C}^{+}$, and the calculation of the mean annual revenue per extra WEC $\Re_{A}$ :

$$
\Re_{A}=\frac{A E P \times F I T}{N_{W E C}^{+}}
$$

The feed-in tariff (FIT) has been first assumed to be between 200 and $600 € / \mathrm{MWh}$, which is representative of FITs that could be used to encourage the MRE development in different countries [17], [18], and then extended up to $1000 € / \mathrm{MWh}$ to break even. The first step is to determine the manufacturing costs of the WEC structure $M_{\text {struct }}$ in $€ / \mathrm{yr}$, which take into account device access, reaction plate, vertical column and surface float:

$$
\begin{gathered}
M_{\text {struct }}=C_{\text {struct }} \times C_{y r}, \\
\text { where, } C_{y r}=\frac{D 2 E \times P_{W E C} \times i n}{A M O},
\end{gathered}
$$

where, $C_{\text {struct }}$ is the cost of the structure, which has been evaluated to $6070 \$ / \mathrm{kW}$ considering an industrialized production (more than $100 \mathrm{WECs}$ ). The conversion between US Dollars and Euros is estimated using the mean value of the last 5 years mean conversion rate (from 2014 to 2019), i.e. $D 2 E=0.89 € /$ USD [19]. Term $P_{W E C}$ corresponds to the rated power of a single WEC in $\mathrm{kW}$, and $A M O$ represents the amortization period, which is 20 years, i.e. the typical estimated service life of a wave farm. As the costs are calculated using a 2014 cost breakdown analysis, the term in represents the inflation rate until 2020, which is $5.2 \%$ [20]. In this study, we also considered that extra WEC(s) are financed without extending credit or any additional subsidies. Next step is the evaluation of the Manufacturing costs of the power conversion chain $M_{P C C}$ in $€ / y r$, which includes all the components that converts the wave movements into electricity, i.e. PTO, generator, transformer, power converter, dynamic 
cable, etc. . The costs related to some parts of the hydraulic and electrical costs are removed since we consider direct drive point absorbers with no energy storage.

$$
M_{P C C}=C_{P C C} \times C_{y r},
$$

where, $C_{P C C}$ is the cost of the whole power conversion chain (PCC), which has been evaluated to $1110 \$ / \mathrm{kW}$. It is also necessary to take into account the manufacturing costs of the moorings and the associated buoyancy and anchoring system $\left(M_{\text {moor }}\right)$ in $€ / \mathrm{yr}$ :

$$
M_{\text {moor }}={ }_{\text {moor }} \times C_{y r},
$$

where, $C_{\text {moor }}$ has been evaluated to $1651 \$ / \mathrm{kW}$. Then, one has to consider the deployment and installation costs $(D I)$ of both the additional WECs $\left(N_{W E C}^{+}\right)$and their mooring systems with :

$$
D I=C_{I}\left(N_{W E C}^{+}\right) \times C_{y r},
$$

where $C_{I}$ is the cost of installation in $\$ / \mathrm{kW}$ that highly depends on $N_{W E C}^{+}$, as depicted in Fig. 3. The last item to consider is the operating, maintenance and monitoring annual costs $O M M$ in $€ / y r$. Term $O M M$ depends on the total number of WECs $N_{W E C}^{t o t}$ that are installed in the farm, as depicted in Fig. 4.

$$
O M M=C_{O M M}\left(N_{W E C}^{t o t}\right) \times D 2 E \times P_{W E C} \times i n,
$$

Finally, the revenue per WEC $\Re_{W E C}$ can be evaluated considering the income minus the sum of all the annual expenses $(A E)$ described above, i.e.

$$
\begin{gathered}
\sum A E=M_{\text {struct }}+M_{P C C}+M_{\text {moor }}+D I+O M M \\
\Re_{W E C}=\Re_{A}-\sum A E,
\end{gathered}
$$

\section{CASE STUDY DESCRIPTION}

The objective is to determine the number of additional WECs that could be installed in this virtual farm without exceeding temperature constraints and regarding the economic performance of each WEC. To do so, our case study considers a variable size wave farm (in terms of WEC number) and the associated energy production over 12 months using sea-states sequence of the SEM-REV test site from June 2014 to June 2015. More precisely, we performed our simulations over a 18-month period, but we only retained the last 12 months for the analysis. Indeed, the first 6 months were considered as an initialization step at the start of which the cable was energized and where the observed transients (i.e. slow temperature rise of the cable and of its environment) where not relevant for this analysis. Retaining the last 12 months allows to consider a wave farm under normal operationg conditions. Then, three different scenarios are considered:

- Case 1: The number of WEC is kept constant where $N_{W E C}^{i}$ corresponds to the maximum number of WECs that can be connected to the wave farm without exceeding the constant current carrying capacity of the cable $I_{c c}$, i.e.

$$
\left.\max \left(I_{f a r m}(t)\right)\right|_{N_{W E C}^{i}} \leq I_{c c}
$$

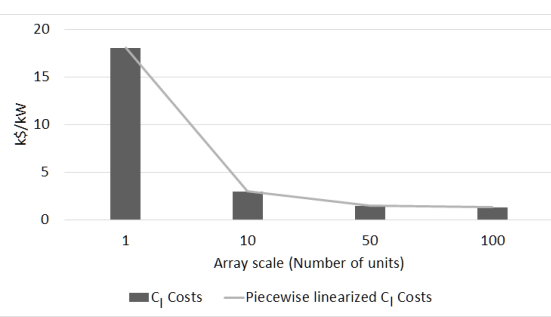

Fig. 3. Installation costs per deployment scale. The figure represents the full cost that can be amortized over several years (20 yr in our case study) [16]

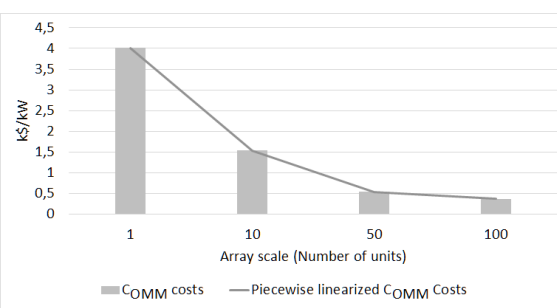

Fig. 4. Operating, maintenance and monitoring annualized costs per deployment scale [16]

- Case $2: N_{W E C}^{T}$ is also kept constant and corresponds to the maximum number of WECs that can be connected to the farm without exceeding temperature constraints, i.e.

$$
\left.\max \left(T_{\text {core }}(t)\right)\right|_{N_{W E C}^{T}} \leq T_{\max }
$$

- Case $3: N_{W E C}^{v a r}$ is allowed to vary by (de)activating WECs between different sea-states. However, the temperature constraints must still be satisfied, i.e.

$$
\left.\max \left(T_{\text {core }}(t)\right)\right|_{N_{W E C}^{v a r}(t)} \leq T_{\max }
$$

Case 1 is considered to be the initial and existing WEC farm, where only maximum current constraints were considered to determine the number of WECs, which has been shown to be a conservative approach in previous work [4]. Case 2, where $N_{W E C}$ remains constant, temperature constraints instead of current constraints are considered. Finally, Case 3 represents a further enhancement compared to Case 2, where variations of $N_{W E C}$ are allowed during the simulation. Considering the economic aspects, we assumed that the initial farm, that is composed of 11 WECs, was already installed. Following this assumption, its costs are not taken into account, and the techno-economic study only considers the energy output and associated revenues and costs of extra WEC(s).

\section{RESUlts}

\section{A. Case 1}

As we can see in Table I, which summarized the simulation results, considering current criteria in Case 1 leads us to determine that the initial farm is composed of 11 WECs. Indeed, it is the only case where the maximum value of the RMS current $I_{\max }$ does not exceed $I_{c c}$. Such a conservative approach, i.e. based on maximum current constraint, may be 

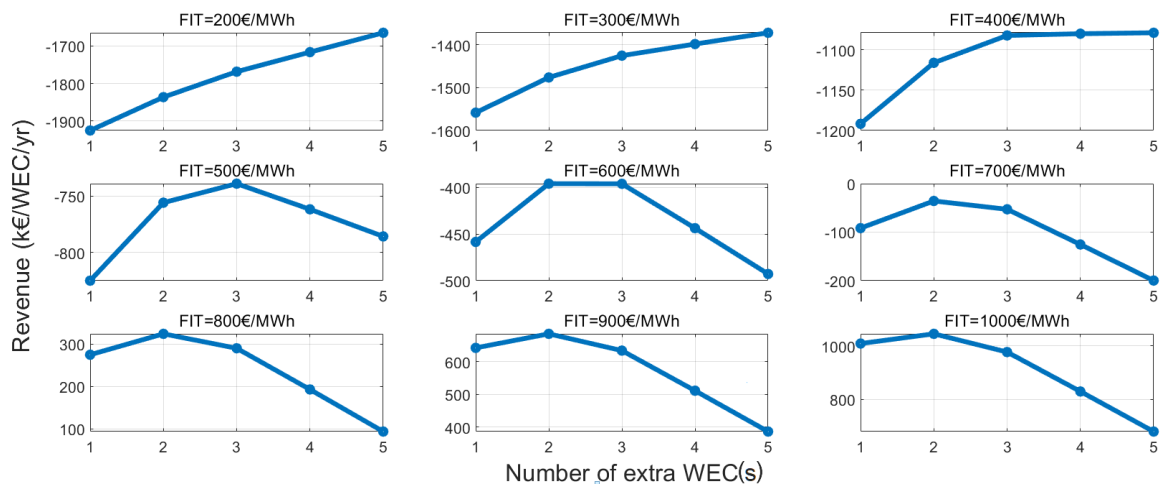

Fig. 5. Results of the techno-economic studies regarding the mean revenue of the additional WEC(s) $N_{W E C}^{+}$and considering different FITs.

TABLE I

RESULTS OF THE CASE STUDY.

\begin{tabular}{ccccc}
\hline $\begin{array}{c}\text { Number } \\
\text { of WECs }\end{array}$ & $\begin{array}{c}\text { Energy } \\
(\mathrm{GWh})\end{array}$ & $\begin{array}{c}T_{\max } \\
\left({ }^{\circ} \mathrm{C}\right)\end{array}$ & $\frac{I_{\max }}{I_{c c}}$ & $\begin{array}{c}\mathrm{AEP}^{+} \text {per extra } \\
\text { WEC }(\mathrm{MWh})\end{array}$ \\
\hline $11^{*}$ & 39.9 & 68.5 & 0.96 & 0 \\
$12^{\&}$ & 43.6 & 81.85 & 1.05 & 3667 \\
$13^{\&}$ & 47.2 & 97.8 & 1.14 & 3607 \\
11 to $13^{\#}$ & 47.1 & 90 & 1.14 & 3536 \\
11 to $14^{\#}$ & 50.2 & 90 & 1.22 & 3091 \\
11 to $15^{\#}$ & 52.7 & 90 & 1.31 & 2435 \\
11 to $16^{\#}$ & 54.6 & 90 & 1.40 & 1923 \\
11 to $36^{\#}$ & 70 & 90 & 2.87 & 771 \\
\hline
\end{tabular}

${ }^{+}$Mean value calculated for each extra WEC.

* Considered as the reference case, i.e. the farm initially installed on the wave energy site resulting from Case 1.

\& Resulting from Case 2

\# Resulting from Case 3 .

irrelevant in the case of wave energy farms that can generate highly fluctuating current profiles, especially when no energy storage is installed.

\section{B. Case 2}

According to the simulation results, it would be technically possible to permanently add one WEC, i.e. the farm would be composed of 12 WECs if we consider thermal constraints instead of current constraints. Under these conditions the current can reach up to 1.05 time $I_{c c}$ and the temperature remains below $90{ }^{\circ} \mathrm{C}$. Compared to Case 1 , the energy production is increased by $9.2 \%$. Switching permanently to $13 \mathrm{WECs}$ is not possible because, under these conditions, the cable core temperature would reach $97.8{ }^{\circ} \mathrm{C}$, which exceeds the maximum temperature of $90{ }^{\circ} \mathrm{C}$.

\section{Case 3}

First of all, we do not consider any economic aspects, i.e. the farm is composed of 11 to 36 WECs. The results show that it is technically possible to drastically increase the production of energy compared to Case 1. Indeed, by switching a variable number of WECs on or off for each period of 30 minutes, it is possible to roughly control the power produced with respect to the thermal constraints. Under these conditions, the temperature is closer to the maximum temperature of the cable over the entire considered period, which means that the cable is approaching its optimal use. Under these conditions, the power production is $175 \%$ more (with 36 WECs) than this of Case 1 while $I_{\max }$ can reach 2.9 times $I_{c c}$. To have an optimal use of the cable, one can add more WECs to increase the production during the lowest wave energy phase, but this means also that each WEC will be shed more often and over a longer duration during more energetic periods, thus decreasing its $A E P$ and therefore its associated revenue. Then, it is quite a nonsense to add WECs without considering economic aspects. Based on this observation, we performed a simple techno-economic analysis to determine the optimized number of WECs that maximizes the revenue per extra WEC without exceeding the thermal constraints of the cable. The results of the techno-economic study are presented in Fig. 5. The first observation concerns the optimal number of extra WECs, which depends on the FIT. One can see that 2 extra WECs seems to be optimal for our case study when considering economic aspects, which leads to increase the production by $18 \%$ without any modification of the export cable. The revenue is indeed positive, and maximal, when 2 WECs are added to the farm (FIT greater than or equal to $800 € / \mathrm{MWh})$. One can remark that the break-even point is between 700 and $800 € / M W h$. Such targeted FITs, that do not take into account taxes, are in agreement with [16], where the calculated LCOE for a similar WEC farm in terms of number of WECs, i.e. from 12 to 16 , is approximately $1300 € / \mathrm{MWh}$. This means that, even with an already funded and installed infrastructure, the decision of adding WECs to increase the use of this infrastructure while meeting thermal constraints must consider economic aspects, as such an approach is not always economically viable. In particular, in the case of the SEM-REV test site considered in this paper, applying this approach is unrealistic due to the extremely high feed-in tariff it would require, compared to the costs of electricity, even in island territories [21]. It is also important to note that this FIT estimation is made considering a small farm, i.e. the 
costs are distributed only on a small number of WECs. Then, the rentability is directly impacted by the $D I$ and $O M M$ costs that decrease dramatically with the number of WECs, as presented in Figs 3 and 4, but remains extremely high when only few additional WECs are considered. It may therefore be expected that increasing the power capacity of a future, larger-scale farm, (as opposed to a small-scale test site), may be economically viable under lower FIT levels. In this case, the number of additional WECs may not only be of the order of few units but maybe of ten units or so, leading to a dramatic decrease of the $D I$ and $O M M$ costs per WEC. It is also interesting to note that the SEM-REV test site presents mild energy levels, compared to other locations where the average wave power is three to five times more important [2]. The SEM-REV test site presents indeed an annual average power of $12 \mathrm{~kW} / \mathrm{m}$ while the Portuguese pilot zone reaches $32 \mathrm{~kW} / \mathrm{m}$ [2], and Belmullet in Ireland shows an average wave power of nearly $70 \mathrm{~kW} / \mathrm{m}$ [22]. This increased level of available energy may render the proposed approach economically viable, even with small-scale farms. Future work will consist in applying the same methodology to such other locations.

\section{CONCLUSION}

The study described in this paper deals with the nearoptimal use of an existing MRE farm electrical infrastructure by exploiting the thermal inertia phenomenon, while considering also economic aspects. The paper considers a 12-month analysis of the thermal response of a wave farm export cable considering realistic sea-state sequences of the SEM-REV test site. It has been shown that making profitable the extension of a small wave energy farm requires unrealistic feed-in tariffs that are far over the maximum costs of electricity around the world. However, it is important to keep in mind that sites such as SEM-REV are primarily open sea test testing sites dedicated to test and improve MRE systems, i.e. they were not designed for MRE farms. The method we proposed can be used to extend their power export capability at no cost, which could be very interesting to install more MRE converters and/or of larger power. From a WEC farm point of view, it is important to note that the small size of the farm considered in our case study, that was initially designed considering maximum current constraints and is composed of 11 WECs, can be extended to 13 WECs with the combination of the thermal analysis and of a simple techno-economic analysis, which leads to an increase of the energy production of $18 \%$ without modifying the export cable. According to these observations, the results shown in this paper are encouraging for larger MRE farms. Indeed, on a more industrial scale, the deployment of more additional MRE converters allows to distribute the installation, the operating, the maintenance and the monitoring costs over more devices. In other words, one might draw different conclusions with a larger farm, where a $10 \%$ increase of power could lead to add 10 or more MRE converters, leading to drastically lower costs per extra unit. It is also interesting to note that there exist more energetic sites than SEM-REV, which offers higher average annual wave power and for which our approach may be economically viable, even for small-scale farms.

\section{REFERENCES}

[1] S. Astariz , A. Vazquez and G. Iglesias, "Evaluation and comparison of the levelized cost of tidal, wave, and offshore wind energy," Journal of Renewable and Sustainable Energy, 2015, vol. 7, no 5, pp. 1-13.

[2] V. O. Mora-Figueroa, C. Huertas Olivares, B. Holmes, and A. M. O'Hagan. Catalogue of wave energy test centres. Deliverable D2. 1: Catalogue of Wave Energy Test Centres, March 2011.

[3] A. Matine, C.-H. Bonnard, A. Blavette, S. Bourguet, F. Rongère, T. Kovaltchouk, and E. Schaeffer, "Optimal sizing of submarine cables from an electro-thermal perspective," in European Wave and Tidal Conference (EWTEC), 2017.

[4] C.-H. Bonnard, A. Blavette, S. Bourguet and A. Charmetant, "Modeling of a wave farm export cable for electro-thermal sizing studies," Renewable Energy, Volume 147, Part 1, 2020, pp. 2387-2398.

[5] C.-H. Bonnard, A. Blavette, S. Bourguet, et al., "Towards the optimal use of an existing MRE electrical network from an electrothermal perspective," 2019 IEEE PES Innovative Smart Grid Technologies Europe (ISGT-Europe), Bucharest, Romania, 2019, pp. 1-5.

[6] École Centrale de Nantes. (2020) The SEM-REV website. [Online] Available: https://sem-rev.ec-nantes.fr/english-version/

[7] MATLAB, version 9.5.0.944444 (R2018b). The MathWorks Inc., 2018.

[8] A. Blavette, T. Kovaltchouk, F. Rongère, et al., "Influence of the wave dispersion phenomenon on the flicker generated by a wave farm," in European Wave and Tidal Energy Conference (EWTEC), 2017.

[9] T. Kovaltchouk, B. Multon, H. B. Ahmed, et al., "Influence of control strategy on the global efficiency of a direct wave energy converter with electric power take-off," in 2013 Eighth International Conference and Exhibition on Ecological Vehicles and Renewable Energies (EVER), March 2013, pp. 1-10.

[10] E. Boudière, C. Maisondieu, F. Ardhuin, et al.,"A suitable metocean hindcast database for the design of Marine energy converters," International Journal of Marine Energy, Volumes 3-4, 2013, pp. 40-52.

[11] Y. Perignon, "Assessing accuracy in the estimation of spectral content in wave energy resource on the French Atlantic test site SEM-REV," Renewable Energy, Volume 114, Part A, 2017, pp. 145-153.

[12] J. C. Sabonnadiere, "Renewable energy technologies," Vol. 146. John Wiley Sons, 2010.

[13] A. Boglietti, E. Carpaneto, M. Cossale et al., Stator thermal model for short-time thermal transients International Conference on Electrical Machines (ICEM), Berlin, Germany, 2014

[14] P. Magnone, C. Fiegna, G. Greco et al., Numerical simulation and modeling of thermal transient in silicon power devices Solid-State Electronics, vol. 88, pp. 69-72, 2013.

[15] C. H. Bonnard, F. Sirois, C. Lacroix et al., Multi-scale model of resistivetype superconducting fault current limiters based on 2G HTS coated conductors Superconductor Science and Technology, vol. 30, $\mathrm{n}^{\circ} 11$, 2016.

[16] V. S. Neary, M. Lawson, M. Previsic, et al.. Report SAND20149040 : "Methodology for Design and Economic Analysis of Marine Energy Conversion (MEC) Technologies," Sandia National Lab.(SNLNM), Albuquerque, NM (United States), 2014.

[17] J. F. Chozas, J. P. Kofoed and N. E. H. Jensen, "User Guide-COE Calculation Tool for Wave Energy Converters". Aalborg University, Denmark, 2014.

[18] Ocean Energy Systems. An Overview of Ocean Energy Activities in 2018. Annual Report. https://report2018.ocean-energysystems.org/documents/OES-Annual-Report-2018/

[19] Internal Revenue Service of the United States. The IRS website, accessed on february 2020. https://www.irs.gov/individuals/internationaltaxpayers/yearly-average-currency-exchange-rates

[20] Global Rates, Inflation France - indice des prix à la consommation (IPC) Available : https://fr.globalrates.com/statistiques-economiques/inflation/indice-des-prix-a-laconsommation/ipc/france.aspx

[21] Wikipedia contributors. Electricity pricing. In Wikipedia, The Free Encyclopedia. Accessed April 2020: https://en.wikipedia.org/w/index. php?title=Electricity $\backslash$ pricing $\backslash$ \&oldid=952029301

[22] W. Sheng and T. Lewis."Energy conversion: A comparison of fix-and self-referenced wave energy converters" Energies 9.12 (2016): 1056. 